\title{
O desenvolvimento humano na perspectiva histórico-cultural: relações entre a organização das condições de ensino e a produção da queixa escolar na educação infantil
}

\author{
Human development under historical-cultural approach: relations \\ between the organization of teaching conditions and the production of \\ school complaints in early childhood education
}

Célia Regina da Silva ${ }^{1}$

\begin{abstract}
RESUMO
O presente estudo propõe uma reflexão sobre as concepções que norteiam a organização das condições de ensino na educação infantil, com o intuito de analisar, sob a perspectiva da psicologia histórico-cultural, algumas determinações que constituem o processo de produção das queixas escolares nesse nível de ensino. Para tanto, apresenta análises de três situações que ocorreram no cotidiano de uma escola pública de educação infantil, extraídas de nossa tese de doutorado. As análises revelam as influências das concepções espontaneístas de desenvolvimento humano, as quais levam à organização de condições de ensino propícias à ocorrência de conflitos entre adultos e crianças. Por fim, aprofunda os conceitos de desenvolvimento psíquico e periodização, na perspectiva histórico-cultural com ênfase na transição entre a primeira infância e a idade pré-escolar, denominada como crise dos três anos, demonstrando incompatibilidades entre as necessidades psíquicas das crianças e a forma como as condições de ensino, apresentadas nas situações descritas, estão organizadas.
\end{abstract}

Palavras-chave: Desenvolvimento infantil. Condições de ensino. Queixa escolar.

\begin{abstract}
The present study proposes a reflection on the conceptions that guide the organization of teaching conditions in early childhood education, in order to analyze, from the perspective of historical-cultural psychology, some determinations that constitute the process of producing school complaints at this level of education. For this purpose, it presents analyzes of three situations that occurred in the daily life of a public school of early childhood education, extracted from our doctoral thesis. The analyzes reveal the influences of spontaneistic conceptions of human development, which lead to the organization of teaching conditions conducive to conflicts between adults and children. Finally, this study deepens the concepts of psychic development and periodization, in the historical-cultural perspective with emphasis on the transition between early childhood and preschool age, called the three-year crisis, demonstrating incompatibilities between children's psychic needs and the way the teaching conditions, presented in the situations described, are organized.
\end{abstract}

Keywords: Child Development. Teaching conditions. School complaint.

\footnotetext{
${ }^{1}$ Célia Regina da Silva, Doutora pelo Programa de Pós-graduação em Educação Escolar da Faculdade de Ciências e letras da Unesp/Araraquara-SP e Docente do curso de graduação em Pedagogia da Universidade de Mogi da Cruzes-SP, Brasil. E-mail: crsilvau@gmail.com
} 


\section{Introdução}

[...] duas questões se colocam diante do pedagogo, em primeiro lugar a do estudo individual de todas as particularidades específicas de cada educando em particular, em segundo, do ajuste individual de todos os procedimentos de educação e interferência do meio social em cada uma delas. Nivelar todas elas é o maior equívoco da pedagogia e sua premissa básica requer, forçosamente a individualização: requer a definição consciente e precisa dos objetivos individuais da educação para cada aluno. (Vigotski, 2010, p. 431).

O presente trabalho deriva de nossa tese de doutoramento e busca apresentar algumas reflexões sobre a relação entre as necessidades presentes no desenvolvimento infantil, segundo a psicologia histórico-cultural, e a organização das condições de ensino na educação infantil, com o intuito de analisar, sob essa perspectiva, algumas determinações que constituem o processo de produção das queixas escolares nesse nível de ensino, cuja consequência, em última instância, tem sido o encaminhamento de alunos e alunas para serem atendidos por profissionais da área de saúde mental.

Compreender as condições vigentes na educação infantil exige reconhecer que o atendimento institucional oferecido pelo Estado às crianças pequenas deve ter caráter educativo, sendo este reconhecimento um fato recente na história do Brasil. Apesar do preceito constitucional de que a educação da criança em seus primeiros anos de vida é "direito da criança, dever do Estado e opção da família" (BRASIL, 1988) ${ }^{2}$, foi somente com a $\mathrm{LDB} / 96^{3}$ que se instituíram os parâmetros para a operacionalização desse "dever" do Estado por meio da inserção da educação infantil no rol de responsabilidades dos setores da educação e não mais da assistência social como vigorara até então. Trata-se de uma conquista fundamental rumo à garantia de direitos infantis, porém, a efetividade da

\footnotetext{
2 BRASIL, 1998. Ministério da Educação e do Desporto, Secretaria de Educação Fundamental. Referenciais curriculares nacionais para a educação infantil. Brasília: MEC/SEF, 1998. Disponível em: http://portal.mec.gov.br/seb/arquivos/pdf/volume3.pdf. Acesso em: 22 jul. 2018

3 BRASIL, 1996. Planalto do Governo. Lei de Diretrizes e Bases. Lei $N^{o}$ 9.394, de 20 de dezembro de 1996. Estabelece as diretrizes e bases da educação nacional. Brasília, 1996. Disponível em: http://www.planalto.gov.br/ccivil_03/LEIS/L9394.htm. Acesso em: 22 jul. 2018.
} 
incorporação da educação infantil como primeiro nível da educação básica exige a formulação de propostas de trabalho de caráter fundamentalmente educativo, as quais, por sua vez, engendram determinadas concepções sobre infância, educação e sociedade.

No que se refere às concepções sobre infância e educação, a implementação de políticas para a educação infantil tem revelado inúmeras divergências de cunho teórico e prático relacionadas à caracterização do trabalho do professor que atua nesse nível de ensino; entretanto, se o trabalho com a criança em seus primeiros anos de vida é regulamentado pelas políticas em educação, faz-se necessária a definição sobre o que seja educar e como deve-se atuar junto às crianças dessa faixa etária em contexto escolar.

Muito se tem produzido com a intenção de apresentar respostas para os questionamentos acima; contudo, ao considerarmos os estudos sobre o tema, constata-se que ainda não chegamos, ao menos, a um consenso em relação ao uso da palavra "ensino", para expressar o que se deve fazer na escola com crianças dessa faixa etária, como mostram Arce e Martins (2013) ao defenderem a centralidade do ensino na educação infantil.

Nosso percurso profissional na área tem nos mostrado que, de modo geral, o esforço para superar as práticas de cunho assistencialista, que caracterizavam o funcionamento das instituições de educação infantil em suas origens, tem apresentado, como uma de suas implicações, uma organização de condições de ensino pautadas em práticas a partir das quais ocorre uma supervalorização de atividades pedagógicas associadas à reprodução de estratégias e conteúdos, supostamente, preparatórios para o ensino fundamental. Tal aspecto relaciona-se com o problema da produção da queixa escolar; pois esse processo de transformação da educação infantil em "sala de espera" do ensino fundamental não tem se limitado aos equívocos relacionados à forma e ao conteúdo a ser ensinado para crianças pequenas.

Um sintoma alarmante que revela a gravidade das consequências dessa imitação mecânica de algumas práticas frequentes no ensino fundamental é o crescimento do número de crianças menores de 5 anos encaminhadas pela escola para avaliação psicológica e/ou psiquiátrica e o consequente uso de medicamentos 
psicofármacos no Brasil, levando alguns órgãos a emitir documentos que apresentam orientações para impedir o uso indevido desse tipo de medicação, como por exemplo o "Recomendações do Ministério da Saúde para Adoção de práticas não medicalizantes e para a publicação de protocolos municipais e estaduais de dispensação de metilfenidato para prevenir a excessiva medicalização de crianças e adolescentes" ${ }^{4}$.

Além disso, o boletim do SNGPC $^{5}$ apresenta uma análise detalhada sobre o consumo de metilfenidato ${ }^{6}$ e aponta as relações entre o consumo desse tipo de substância e a vivência escolar ao revelar a ocorrência de queda no consumo no período de férias escolares. O material mostra, ainda, que o medicamento está sendo ministrado para crianças a partir dos dois anos, apesar da indicação expressa na bula de que o uso só é recomendado acima dos seis anos de idade.

$\mathrm{Na}$ tese de doutorado (Silva, 2017) que deu origem a esse artigo, apresentamos um levantamento de estudos que nos possibilitou ter maior clareza em relação ao avanço e amplitude das explicações que patologizam as condutas infantis; pois constatamos a existência de pesquisas que, sob o argumento da necessidade de se prevenir supostos "transtornos de conduta", postulam a possibilidade de diagnosticar esse tipo de transtorno desde os 18 meses de vida, uma vez que, conforme aponta Dias (2012), a partir dos estudos de Keenan \& Shaw (1998), nessa fase da infância, a criança já pode manifestar comportamentos relacionados à destruição de objetos e à agressão aos pais.

Nosso contato com análises que adotam expressões como "destruir" e "agredir", referindo-se a ações realizadas por crianças de um ano e meio, remetenos à reflexão apresentada por Nosella (2008), que nos alerta em relação aos perigos do distanciamento entre o processo de produção do conhecimento científico e a reflexão ética que nos conduz ao questionamento sobre qual papel que esse tipo de conhecimento deve cumprir na sociedade. Nesse sentido, o autor cita as seguintes palavras do personagem Galileu Galilei de Brecht (1977, p. 224-

\footnotetext{
4 Disponível em: https://www2.camara.leg.br/atividade-legislativa/comissoes/comissoespermanentes/cssf/audiencias-publicas/audiencia-publica-2015/audiencia-24.11/apresentacao$\underline{\text { rubens }}$

${ }^{5}$ Sistema Nacional de Gerenciamento de Produtos Controlados.

${ }^{6}$ Principal componente de medicamento que é indicado para casos de Transtorno de déficit de atenção e hiperatividade.
} 
225): “[...] O precipício entre vocês [pesquisadores] e a humanidade pode crescer tanto, que ao grito alegre de vocês [“eureka”, grito de quem descobriu alguma coisa nova, responda um grito universal de horror [...]”.

Como reflete Nosella (2008) acerca das palavra do personagem do dramaturgo alemão, a perspectiva aqui adotada nos incita a um "grito universal de horror" diante de análises que consideram ser a causa dos entraves no processo de escolarização, aquelas manifestações infantis que, se analisadas em sua concreticidade, revelam ser a consequência de problemas estruturais vivenciados no cotidiano escolar. Diante disso, à luz de uma análise materialista dialética como "método de penetração na essência do fenômeno" (Kopnin, 1978, p. 46), esperamos contribuir para a superação das análises centradas na patologização das ações individuais, hegemonicamente adotadas diante de problemas escolares.

Com base nessas reflexões, o presente texto está orientado pela tese segundo a qual algumas condições em que se desenvolve a prática de ensino na educação infantil compõem o conjunto de determinações e relações que sustentam o processo de produção de queixas escolares, por não atenderem às necessidades dos diferentes períodos do desenvolvimento das crianças. Tomando essa afirmação como elemento norteador de nossa argumentação, iniciaremos apresentando três situações vivenciadas no cotidiano da escola em que a pesquisa que deu origem a esse trabalho foi desenvolvida, as quais servirão como base para nossas análises teóricas.

A partir das situações descritas, conduziremos uma reflexão acerca das influências das concepções hegemônicas sobre infância e educação na organização das condições de ensino apresentadas. Em seguida, estabeleceremos relações entre algumas leis gerais do desenvolvimento psíquico e a periodização do desenvolvimento infantil na psicologia histórico-cultural, destacando transição entre a primeira infância e a idade pré-escolar, para, mais adiante, relacionarmos as condições em que ocorreram as situações, inicialmente apresentadas, e os processos que caracterizam o desenvolvimento psíquico das crianças envolvidas, de acordo com a periodização na psicologia histórico-cultural. Para concluir, apresentamos algumas considerações sobre o processo de produção da queixa 
escolar na educação infantil e o conhecimento científico disponível para a formulação de estratégias voltadas para a organização de condições de ensino comprometidas com a superação desse problema.

\section{As concepções hegemônicas sobre desenvolvimento humano e as} condições em que se produzem as queixas escolares na educação infantil

Para que possamos compreender por que o crescimento da demanda da escola por diagnósticos de transtornos mentais na infância remete-nos aos desafios éticos presentes no processo de produção do conhecimento científico sobre educação infantil no atual contexto, precisamos resgatar elementos históricos que constituem o modo como, hegemonicamente, as crianças e a educação escolar são vistas em nossa cultura. Desde sua origem, a escola divide com a família a função de mediar a relação entre a criança e a sociedade, engendrando, portanto, concepções de infância e de sociedade, nas quais se fundamenta para organizar as condições em que buscará viabilizar seu papel social.

É na dinâmica de cumprimento da função social atribuída à escola que surge o que se convencionou denominar como fracasso escolar, cuja expressão singular corresponde aos casos de queixas escolares. Em suas análises sobre o fracasso escolar, Patto $(1973,1984,1988,1999)$ e colaboradores vêm nos mostrando o caráter classista da educação escolar burguesa e, por meio de seus trabalhos, têm evidenciado o processo que produz o fracasso escolar e suas relações com o preconceito e exclusão da classe trabalhadora no interior das práticas cotidianamente adotadas na escola.

Com base nessas críticas, Beatriz de P. Souza (2007) e colaboradores têm desenvolvido um trabalho que confere um novo olhar para a atuação de psicólogos diante de demandas de queixas escolares, contribuindo para a formulação de análises que superam a culpabilização dos indivíduos e nos direcionam para os múltiplos fatores envolvidos nas circunstâncias em que surgem os casos de queixa escolar. 
Sem desconsiderar a importância do posicionamento crítico dos psicólogos frente ao encaminhamento de crianças por queixas escolares, dedicamo-nos a analisar as relações e determinações que vigoram no cotidiano das escolas de educação infantil, em que se constitui a necessidade de encaminhar alunos e alunas para profissionais da área de saúde mental. A relevância dessa análise assenta-se na constatação de que tal necessidade se constitui a partir do ponto de vista da equipe que atua cotidianamente na escola, o que evidencia a urgência da incorporação, pelos professores e educadores, das análises críticas que já foram consolidadas na atuação de parte dos profissionais da psicologia. Desse modo, tal incorporação pode levantar o questionamento sobre a efetividade da estratégia de encaminhamento para a saúde mental como principal e, por vezes, única forma de solucionar os casos em que a conduta da criança difere daquilo que é esperado para a faixa etária do ponto de vista da equipe escolar.

Um elemento central para refletirmos sobre a produção da queixa escolar na educação infantil é a análise das concepções de infância e de educação que norteiam a organização das condições em que se dão os fatos relacionados à conduta da criança considerada patológica ou que, por quaisquer motivos, é apontada como queixa por parte dos professores, visto que: "A primeira condição para abordarmos dialeticamente qualquer assunto, como já sabemos é colocar-nos no interior dos fatos e processos com que o conhecimento desse assunto se elabora" (Prado Jr., 1963, p. 579).

Partindo dessa premissa, descreveremos três situações extraídas das observações realizadas em uma escola de educação infantil localizada em um município do interior de São Paulo, em função de nossa tese de doutoramento (Silva, 2017). A partir desses contextos, estabeleceremos relações entre o modo como estão organizadas as condições de ensino em cada uma dessas situações e as características do desenvolvimento infantil segundo a psicologia históricocultural. Cabe esclarecer que, inspirando-nos em Pasqualini (2010), estamos considerando como "organização das condições de ensino" elementos que compõe as circunstâncias descritas, tendo em vista as escolhas (relacionadas ao espaço físico, procedimentos adotados e período do desenvolvimento em que as crianças se encontram) feitas pela equipe escolar em função de sua tarefa de garantir o 
desenvolvimento das atividades que envolvem o binômio cuidar/educar ${ }^{7}$, conforme previsto na elaboração do planejamento diário que articula o plano de trabalho a ser desenvolvido pelas educadoras e professoras e a organização da rotina escolar.

A primeira situação corresponde à forma como estavam organizadas as condições em que se dava a recepção das crianças na escola.

\begin{tabular}{|l|}
\hline Situação A - Condições para recepção das crianças \\
Em relação ao funcionamento da escola, observamos a organização da recepção e \\
saída dos alunos do período matutino. Nesse período, os alunos da pré-escola, de \\
3 a 5 anos, permanecem em uma sala assistindo a um vídeo até o momento do \\
café de cada turma, que também ocorre em sistema de rodízio devido ao fato de o \\
espaço do refeitório não comportar todas as turmas simultaneamente. Sendo \\
assim, todas as crianças da pré-escola começam a ser recebidas a partir das \\
7 h30min. numa sala em que um vídeo infantil é transmitido, para que possam \\
aguardar o momento em que serão conduzidas ao café da manhã. O rodízio do \\
refeitório está organizado de modo que a partir das $7 \mathrm{~h} 45$ min. vem a turma das \\
crianças de 5 anos; quinze minutos depois (8h00min.) é a vez da turma das \\
crianças de 4 anos; e, por fim, às 8 h15min. as crianças de 3 anos chegam para \\
tomar o café. Portanto, uma criança de 3 anos que chegar na escola as $7 \mathrm{~h} 30$ min. \\
permanecerá na sala de vídeo por 45 minutos. (Silva, 2017, p. 145)
\end{tabular}

A segunda situação foi observada a partir de uma solicitação feita à pesquisadora pelas profissionais que atuavam no berçário e associa-se ao modo como estava organizada a rotina de atendimento às necessidades dos bebês. Tratase de um fato ocorrido em um dos dias em que a pesquisadora estava na escola e foi solicitada a orientar as educadoras que atuavam no berçário em relação à alta frequência de "mordidas" entre os bebês. A solicitação foi motivada pela reclamação apresentada por um familiar de um dos alunos da turma, que expressa passionalmente sua preocupação com o ocorrido, pedindo "punição aos

\footnotetext{
${ }^{7}$ Pasqualini (2006) apresenta uma análise aprofundada sobre a indissociabilidade entre cuidar e educar na educação infantil, explicitando que o cuidado é um componente inerente ao trabalho educativo junto a crianças pequenas.
} 
culpados" (Silva, 2017, p. 93). Ao ouvir a demanda apresentada pela direção da escola, a pesquisadora dirige-se até a sala da turma em questão e depara-se com a seguinte cena:

\section{Situação B - Condições para atendimento dos alunos do berçário}

Ao chegar na porta da sala, via-se um edredom no chão, sobre o qual estavam sentados nove bebês de 18 meses a 2 anos e 3 meses. As duas funcionárias ali presentes estavam realizando troca de fraldas em um balcão ao canto da sala e se comunicavam de longe com as crianças que estavam no edredom, pedindo a elas que não puxassem o cabelo dos coleguinhas ou que ficassem sentadinhas. Assim prosseguiam dando orientações verbais diversas de acordo com o que elas observavam e com o que as crianças estavam fazendo. A pesquisadora se apresentou e colocou-se à disposição da equipe. Uma das funcionárias, sem sair do fundo da sala, perguntou em voz alta se a pesquisadora poderia ajudá-las, porque estava ocorrendo muitas mordidas e alguns pais estavam "revoltados". Havia muito ruído na sala e alguns bebês estavam chorando. A pesquisadora sentou-se junto às crianças, começou a cantar uma música infantil. As crianças começaram a tentar imitar os gestos e a cantar a música que a pesquisadora estava cantando, fazendo com que diminuísse o ruído do ambiente. As funcionárias concluíram a troca de fraldas e uma delas informou às crianças que todos iriam brincar no tanque de areia. A pesquisadora acompanhou a turma até o tanque de areia e continuou conversando com a funcionária que lhe falava: “alguns pais não entendem que eles estão nessa fase de morder". Ela continuou dizendo que elas trabalham em três profissionais, entretanto, durante o período observado, somente duas estavam com o grupo de crianças, estando a terceira realizando atividades relacionadas à organização de lembrancinhas para festas e outras questões burocráticas. (Silva, 2017, p. 204)

A terceira situação descrita envolve condições em que a professora se depara com a necessidade de se dedicar a atividades alheias àquelas que estão sendo desenvolvidas pelas crianças, a partir de sua orientação inicial, visto que a professora encontra-se confeccionando enfeites para a festa da família. Vejamos a 
terceira situação:

Situação C - Condições em que atividades relacionadas ao preparo de eventos comemorativos se sobrepõem ao acompanhamento da atividade proposta às crianças.

[...] Agora senta aí com seus colegas e escolhe um brinquedo pra você - orienta a professora Dora ${ }^{8}$. Vítor ${ }^{9}$ balança a cabeça afirmativamente e pega um carrinho, indo se sentar em uma das mesas em que estão as outras crianças. Sentado, Vítor simula com a boca o barulho do motor do carro e desliza-o sobre a mesa. Nesse deslizar do carrinho, Vítor se levanta para realizar movimentos mais amplos, passando o carrinho por toda a mesa. Uma criança diz: “- Pára, Vítor!". Dora, que está fora da imagem, diz: “- O que que é, hein? Ah, eu vou guardar os brinquedos!" Nesse momento, a câmera foca Dora, que está fazendo os coraçõezinhos vermelhos na sua mesa. A câmera retorna a Vítor, que continua com seu carro de motor barulhento a passear, agora, pelas estantes da sala, sob os olhares das crianças da mesa em que ele estava. Uma delas exclama: “- Tia Dora, olha o Vítor!” Dora responde: “- Vítor!!!” Ele continua a ziguezaguear com seu carrinho pelas paredes, estantes e chão da sala, agora seguindo rumo à porta. Ao chegar à porta, Vítor olha para Dora, dá uma rápida olhada para a câmera, solta o carrinho no chão e sai pelo corredor. A câmera o segue corredor afora. Agora, a câmera está em movimento, focando o chão de uma área semiinterna, onde se vê um foco de luminosidade mais forte no corredor e, ao fundo, à esquerda, um fogão. Quando a câmera vira à esquerda, passando pelo fogão, dá de frente com Vítor, olhando para ela. A pesquisadora pergunta a ele: “- O que você vai fazer?" Ele vem até ela oferecendo um rolo de arame. A Pesquisadora convida-o: “- Vamos entregar o rolo de fio para Dora?” Ele aceita e a acompanha, mas antes pergunta a ela: “- O que é o rolo?” A Pesquisadora responde: “-É um fio. Vamos entregar para professora..." Ele sai correndo na frente, seguido pela pesquisadora. Ele chama Dora, antes de entrar na área interna, virando à esquerda, até chegar na sala de aula mostrando o rolo de fio à Dora. Dora diz: “- 
Deixa eu ver, me dá aqui. Ah é um fio, mas onde você foi buscar esse fio? É pra sair da sala sem a professora, Vítor?" Vítor olha atento para ela, sem responder. Ela orienta: “- Vai sentar lá no seu lugar”.

Vítor acata à orientação, ao voltar à mesa ele nota que o carrinho com o qual brincava antes de sair da sala está nas mãos de outro aluno, que desliza o carrinho pela mesa. Vítor põe, abruptamente, a mão sobre o carrinho e diz com voz chorosa: “- Me dáaaaaa! Oh, tia, ele pegou meu carrinho!” Dora exclama: “Ah mas você saiu da sala, agora o carrinho é dele!” Vítor chora e continua: “- Me dáaaaa!" Puxa o carrinho da mão do colega. Ainda na sua mesa, fora do foco da câmera, Dora diz: “- Deixa com ele, [nome da criança que teve o carrinho puxado por Vítor]". Pega outro mais bonito para você! O menino desfaz o semblante choroso e vai buscar outro carrinho. Vítor voltou a imitar o barulho do motor do carro com a boca, ao mesmo tempo em que o desliza sobre a mesa. Dora, ainda fora do foco da câmera, diz: “- Nossa! Já é essa hora? Ai, menina, essas coisinhas tomam muito tempo da gente! Guardem os brinquedos! [...]” (Silva, 2017, p. 233234).

As situações A, B e C descrevem cenas do cotidiano de uma escola de educação infantil específica, porém retratam problemas recorrentes nesse segmento educacional. A seguir, destacaremos alguns indícios das concepções de infância, desenvolvimento humano e educação que nortearam a organização das condições de ensino retratadas em cada uma delas.

1.1 Análise das concepções norteadoras da organização das condições de ensino retratadas nas situações descritas

Para análise das concepções de infância e de educação que influenciaram a organização das condições de ensino explicitadas na situações descritas, partiremos das explicações que foram apresentadas para a pesquisadora, por meio de diálogos na própria cena ou fora dela, com a equipe escolar durante a realização da pesquisa, como justificativa para que as condições de ensino fossem organizadas da maneira como se apresentam nas três situações descritas. 
Destacamos aqui que se trata de inferências analíticas elaboradas em função dos propósitos desse artigo, visto que esse não era o principal objeto de investigação da pesquisa.

$\mathrm{Na}$ situação A, podemos notar que na forma como está organizado o rodízio para o café da manhã prioriza-se que as crianças com mais idade permaneçam menos tempo na sala de vídeo. Nos diálogos entre a pesquisadora e alguns membros da equipe escolar alega-se a necessidade de se garantir que essa turma fique mais tempo em atividade pedagógica dirigida, ou seja, sendo a primeira turma a fazer uso do refeitório, as crianças dessa turma ficam liberadas para dar início à atividade planejada pela professora antes que todas as outras. Desse modo, a turma que permanece mais tempo assistindo ao vídeo na sala em que ocorre a recepção das crianças é a turma de crianças com menos idade, qual seja, a turma com crianças de 3 a 4 anos. Segundo a equipe escolar, tal aspecto justifica-se pela natureza e propósito das atividades pedagógicas desenvolvidas com essas crianças após o café, visto que, no que se refere a essa faixa etária, as atividades dirigidas pela professora devem ser breves, pois são vistas como cansativas e desgastantes.

Como menciona Duarte (1998), essa concepção negativa em relação às atividades dirigidas pela professora, ou seja, em relação ao ato de ensinar, associa-se aos preceitos do construtivismo, a partir dos quais se postula a valorização da espontaneidade no desenvolvimento intelectual da criança, apontando o direcionamento do professor como ação indesejável, por ser um obstáculo para esse avanço "espontâneo". Rossler (2006, p. 218), ao analisar autores construtivistas, afirma:

[...] ao contrapor um conhecimento metódico, analítico, racional a um conhecimento apaixonado, erotizado, lúdico, esses autores dão margem a interpretações que consideram o primeiro caso um tipo de conhecimento "maçante", "denso", "pesado", "trabalhoso", "exaustivo" (em suma "chato") que só traz "infelicidades" e, o que é pior, inverdades. Ao contrário do outro que pode assumir conotações positivas como algo "prazeroso", "leve", "poético", "alegre", "descontraído", "lúdico", "de fácil acesso", "infantil”, etc.

Portanto, a rotina de recepção e café tem sua organização orientada por uma concepção de desenvolvimento que hierarquiza a importância das atividades 
dirigidas, pautando-se na necessidade de garantir que as crianças cuja idade está mais próxima da faixa etária do ensino fundamental permaneçam mais tempo em atividades voltadas para o ensino de conteúdos sistematizados, ao mesmo tempo em que minimiza a importância desse tipo de atividade para as crianças menores, por considerar que, nesse período, a sistematicidade e diretividade na condução das atividades atuam contra as necessidades psicológicas das crianças.

$\mathrm{Na}$ situação B, a preocupação em concluir a troca de fraldas de todas as crianças o mais rápido possível leva a uma condição em que as duas educadoras permanecem envolvidas com essa atividade, distribuindo alguns brinquedos para que as crianças fiquem manuseando-os enquanto elas trocam a fralda das demais. Essa estratégia traz como expectativa a ideia de que as propriedades físicas dos brinquedos por si só manteriam as crianças envolvidas com o manuseio desses objetos, evitando ações indesejáveis, como as mordidas por exemplo. As educadoras permanecem trocando fraldas e, ao mesmo tempo, observando as crianças que estão manuseando brinquedos no edredom e tentando evitar que elas realizem ações inadequadas por meio de orientações verbais.

Novamente vemos uma situação organizada a partir de uma concepção naturalizante do desenvolvimento infantil, pois supõe-se que, sendo o brinquedo adequado para a idade, a criança se envolverá com sua exploração naturalmente. O comentário da educadora evidencia essa naturalização, em que se relaciona, de forma linear, a idade cronológica da criança com condutas supostamente típicas para o período. Ao afirmar que "alguns pais não entendem que eles estão nessa fase de morder", o ato de morder é apontado como um fenômeno imanente, ou seja, é tomado como uma manifestação vinculada a uma necessidade inerente à condição de desenvolvimento nesse período. Do ponto de vista conceitual, a expressão da educadora remete-nos às formulações teóricas da psicanálise, a partir das quais se postula a fase oral como um período do desenvolvimento, em que a oralidade se impõe como a principal forma de interação da criança com seu entorno. Entretanto, a expressão usada pela educadora carece de cientificidade e revela um processo de vulgarização da teoria psicanalítica, cujos conceitos foram incorporados ao senso comum de forma distorcida, resultando em formulações pseudocientíficas. Trata-se de um tipo de conhecimento que nos aparece com uma 
roupagem científica e vai sendo assumido como explicação, sem que haja um estudo aprofundado das teorias que lhe dão sustentação e que, por vezes, atende mais facilmente à necessidade de apresentar explicações científicas para alguns fenômenos observados no cotidiano:

A ciência desperta um sentimento sublime de admiração. Mas a pseudociência também produz esse efeito. As divulgações escassas e malfeitas da ciência abandonam nichos ecológicos que a pseudociência preenche com rapidez. Se houvesse ampla compreensão de que os dados do conhecimento requerem evidência adequada antes de poder ser aceitos, não haveria espaço para a pseudociência. Mas na cultura popular prevalece uma espécie de Lei de Gresham, segundo a qual a ciência ruim expulsa a boa. (Sagan, 1996, p. 14).

Nosso percurso de atuação na educação infantil desde o período em que esse segmento estava sob responsabilidade dos setores de assistência social tem nos permitido constatar que, frequentemente, as explicações pseudocientíficas sobre o desenvolvimento infantil são adotadas como forma de cientificizar essa atividade para lhe garantir o caráter educativo que a diferenciaria das práticas assistenciais que lhe deram origem. Tais explicações influenciam as decisões relacionadas à organização das condições de ensino a serem adotadas na rotina e são, em alguma medida, reforçadas pela concepção de infância presente nos documentos oficiais que norteiam as práticas da educação infantil, como revela Maria Cecília B. R. de Souza (2007, p. 35),

\begin{abstract}
Neste sentido, o RCNEI indica uma concepção de criança responsável por todos os seus feitos. Confunde erroneamente, autonomia com independência, quando, ao propor uma discussão baseada nos princípios piagetianos do desenvolvimento moral, não leva em consideração que, nesta visão teórica, a criança só conquista a autonomia - como uma possibilidade e não como um pressuposto - após os seis anos de idade, quando se encontra num estágio de desenvolvimento posterior à primeira infância ${ }^{10}$.
\end{abstract}

10 Ainda que atualmente tenhamos outro documento que se constitui como referência oficial no que se refere à organização dos conteúdos escolares, a análise de Portelinha et al. (2017) sobre as concepções presentes na Base Nacional Curricular Comum revela que não há diferença significativa tanto no que se refere à concepção de infância quanto ao papel a ser exercido pelo professor, reafirmando uma perspectiva espontaneísta e naturalizante, tal como ocorre no Referencial Curricular Nacional para Educação Infantil (RCNEI). 
$\mathrm{E}$, por fim, na situação $\mathrm{C}$, registramos algo muito frequente no cotidiano das escolas de educação infantil, que são as demandas operacionais relacionadas aos eventos comemorativos, cuja realização é solicitada aos professores e educadores e precisa ocorrer paralelamente ao desenvolvimento do trabalho de acompanhamento pedagógico das atividades efetuadas pelas crianças. A situação $\mathrm{C}$ evidencia que a professora distribuiu objetos diversos para que as crianças brincassem enquanto ela se dedicava à confecção de materiais decorativos para a festa da família, ato coerente com a responsabilidade que lhe foi atribuída na divisão de tarefas preparativas para a referida festa. Sua expectativa era de que esses brinquedos por si só desencadeassem o interesse das crianças, conduzindo seus atos de modo a evitar comportamentos que fugissem da orientação dada por ela.

Saviani (2005) apresenta elementos para refletirmos sobre o risco relacionado à função que os eventos comemorativos podem assumir no cotidiano escolar, esclarecendo que as atividades atreladas à organização dessas comemorações não correspondem àquilo que é a função essencial da escola e que, portanto, não deveriam ocupar um lugar de maior relevância em relação às atividades que garantem o cumprimento da função primordial da instituição escolar em todos os níveis de ensino, qual seja: a transmissão dos conhecimentos clássicos historicamente acumulados pela humanidade, conforme as condições de apropriação dos alunos e alunas em cada período de seu desenvolvimento.

De modo geral, em nossa análise das três situações descritas, identificamos indícios de uma concepção abstrata sobre o desenvolvimento infantil. Tal concepção, que tem suas raízes na perspectiva construtivista, reiterada pelas políticas de educação infantil no Brasil, é confrontada pelos atos empiricamente manifestos pela criança, que se apresenta aos olhos do professor como um ser alheio ao seu controle, fetichizado ora como ser dependente e frágil, ora como ser autônomo que controla seus atos intencionalmente. A história da educação infantil nos fornece subsídios para compreendermos a gênese dessa ambiguidade nas concepções sobre o desenvolvimento infantil em contexto escolar:

[...] a educação para as crianças pequenas no Brasil, iniciada no final do século XIX, concebeu a criança ora como incapaz, ora como 
criança abstrata, desconsiderando, portanto, suas possibilidades e potencialidades, e forjando um modelo de educação institucional que se baseou essencialmente no projeto assistencialista, legitimado pelas políticas estatais.

Oriunda desse modelo, surge uma idéia entre os educadores, de que a criança pobre precisa ser doutrinada, alimentada e subordinada a tarefas que objetivam a escolarização precoce em detrimento das atividades de cunho educativo com vistas à valorização de suas capacidades. (Souza, M. C. B. R. de, 2007, p. 25).

Essa oscilação entre tomar a criança como ser frágil e, ao mesmo tempo, compreendê-la como ser autônomo, cujas reações são fetichizadas como um fenômeno "fantasmagórico" sobre o qual as condições de ensino não exercem nenhuma influência, resulta da incompatibilidade entre as abstrações em relação às características previstas para cada faixa etária e as ações infantis empiricamente observadas no cotidiano escolar. A respeito das relações entre abstrato e empírico no que se refere ao objeto da psicologia, Saviani (2004, p. 44) ressalta:

Entendo, pois, que, colocando-se numa perspectiva marxiana, a psicologia deveria tomar como seu objeto, não o indivíduo empírico, como ocorre predominantemente, mas o indivíduo concreto. O empírico é aquilo que cai sob o campo da nossa percepção sensível; é o aparente, aquilo que aparece diante de nós. É, portanto, de certo modo, uma abstração, pois nossa percepção sensível não alcança as múltiplas conexões e relações que o configuram.

Diante disso, entendemos que é do desencontro entre abstrato e empírico que emerge o discurso que afirma a incompatibilidade entre teoria e prática. À medida que a psicologia afirma tendências naturais que devem se manifestar em cada idade e professores deparam-se cotidianamente com manifestações infantis muito distantes daquelas que encontram nos textos, abre-se o espaço para as hipóteses diagnósticas. Tendo em vista avançarmos na compreensão desse fenômeno, buscamos na psicologia histórico-cultural subsídios para uma análise em que se para recupere, por meio de abstrações, as determinações e relações que deram origem e sustentam as manifestações infantis, de modo a reorganizar as condições de ensino para que as necessidades das crianças estejam contempladas. 
2 Concepção histórico-dialética de desenvolvimento: a periodização do desenvolvimento humano e a transição entre a primeira infância e a infância pré-escolar na perspectiva histórico-cultural

Para que possamos sair da perspectiva fetichizada em relação ao desenvolvimento infantil rumo a uma explicação baseada na análise concreta dos atos da criança, precisamos compreender o desenvolvimento infantil como um fenômeno complexo, cujas determinações podem ser desveladas por meio da análise, sem subtrair-lhe a dinamicidade. Segundo a perspectiva históricocultural, o desenvolvimento humano não pode ser compreendido a partir de ações isoladas, tomadas como indícios de que os alcances do psiquismo atingiram determinadas etapas. De outro modo, de acordo com essa perspectiva, analisar os alcances do desenvolvimento psíquico envolve compreender a relação da criança com o mundo por meio de seus atos e reações, ou seja, por meio de sua atividade.

Nesse sentido, Vigotski (2018) apresenta as leis gerais que regem a dinâmica do desenvolvimento psíquico na perspectiva histórico-cultural, fornecendo as bases para uma análise científica desse fenômeno, fundada no método materialista dialético. $\mathrm{O}$ autor esclarece que compreender cientificamente o desenvolvimento individual envolve, a um só tempo, reconhecer padrões universais que caracterizam o processo do desenvolvimento humano e identificar as especificidades singulares que se expressam no desenvolvimento de um indivíduo situado em determinadas relações sociais que caracterizam sua condição particular.

A primeira lei geral apresentada por Vigotski (2018) é a afirmação de que o desenvolvimento humano está organizado por uma temporalidade complexa e divide-se em períodos com características próprias. Trata-se de um processo cujo ritmo não coincide com o tempo cronológico linear, pois sua cronicidade é cíclica e cada período é condicionado pela situação social de desenvolvimento em que o indivíduo se encontra. Essa lei traz como uma de suas implicações a impossibilidade de qualquer tipo de naturalização das manifestações características presentes em cada idade, como se estas fossem produto de processos endógenos manifestos pelo indivíduo com o passar do tempo. De outro 
modo, o autor evidencia que as regularidades que se expressam em cada período são influenciadas pelas relações em que a criança se encontra inserida, a partir do lugar que ela ocupa nessas relações

A segunda lei geral ressalta o caráter irregular e desproporcional do desenvolvimento das particularidades do psiquismo infantil, de modo que "sempre algum aspecto da vida mental da criança se desenvolve mais rápido e outros mais devagar" (Vigotski, 2018, p.24). Assim, exemplifica o autor, o desenvolvimento da memória não implica, necessariamente, no desenvolvimento do pensamento em igual proporção. Em decorrência dessa lei, cabe considerar que ao observarmos um amplo desenvolvimento da linguagem, por exemplo, não podemos nos relacionar com a criança pautados na expectativa de que o mesmo patamar foi alcançado em relação a outros aspectos do seu desenvolvimento psíquico.

Por fim, Vigotski (2018) apresenta a terceira lei do desenvolvimento como lei da metamorfose, termo que simboliza a ideia de que as mudanças que ocorrem ao longo do desenvolvimento da criança não se dão por mero acúmulo ou somatória de avanços. Trata-se de verdadeiras transformações de modo que as novas conquistas não são uma continuação das capacidades anteriores. O autor exemplifica afirmando que a evolução do engatinhar para o andar ou o avanço do balbucio à fala revelam mudanças qualitativas que alteram substancialmente o lugar que a criança ocupa nas relações em que está inserida, superando por incorporação as manifestações do período anterior. Em decorrência dessa lei fica evidente a necessidade de se compreender cada período do desenvolvimento em sua própria dinâmica e favorecer a evolução das potencialidades relacionadas às capacidades que caracterizam o período em questão. É a partir destas que surgirão novas capacidades e tal fato, mesmo tendo como base o estágio anterior, implica a criação de capacidades totalmente novas, como resultado da complexificação da atividade da criança, mediada pelas relações em que ela está inserida.

As três leis gerais apresentadas contribuem para que possamos compreender a dinamicidade presente na periodização do desenvolvimento, segundo a psicologia histórico-cultural, que confere a essa perspectiva teórica 
uma abordagem diferenciada para explicar o processo a partir do qual se constitui a amplitude das possibilidades de formas de ações a serem apresentadas pelas crianças nos diferentes ciclos de seu desenvolvimento, sempre em conformidade com a situação social de desenvolvimento que se encontram.

Com base nessas leis gerais, Elkonin (1987) apresenta os principais aspectos da periodização do desenvolvimento infantil na perspectiva históricocultural, enfatizando o caráter histórico do desenvolvimento psicológico e destacando que cada período envolve processos específicos, entre os quais observa-se a ocorrência de momentos de transição, que são considerados "críticos", dada a instabilidade que se expressa como consequência da tensão entre a superação do modo como a criança se insere nas relações no período anterior e os novos modos de agir que ainda não se encontram em pleno domínio. Dessa tensão resulta a manifestação de algumas condutas tomadas como marcadores para a constatação de que o salto qualitativo para o próximo período se encontra em curso. Tais períodos, segundo o autor, estão divididos segundo o critério central da atividade-guia do período, que é àquela que mais mobiliza os processos psíquicos em um dado período, por corresponder ao principal modo de ação autônoma da criança (consideradas as limitações que condicionam os alcances possíveis para cada idade) nas relações em que está inserida. Desse modo, os períodos foram assim denominados: primeiro ano, primeira infância, idade pré-escolar, idade escolar, adolescência inicial e adolescência.

Considerando que a situações que estão sob análise nesse texto foram extraídas da observação da rotina de uma escola de educação infantil, fruto de um estudo cujo sujeito de pesquisa era uma criança de 3 anos (Silva, 2017), apresentaremos as características da idade pré-escolar, com ênfase no momento de transição entre primeira infância e idade pré-escolar, denominado como crise dos 3 anos.

Cabe ressaltar que o termo crise sugere um processo exclusivamente individual e subjetivo, porém essa expressão assume outro sentido na psicologia histórico-cultural. Trata-se do reconhecimento de que alteração estrutural, que se efetiva no novo período de desenvolvimento, não se dá de forma abrupta, pois é forjada no lapso de instabilidade que se manifesta no momento em que o novo 
período ainda não vigora plenamente e, no entanto, o período anterior já não mais se encontra em seu funcionamento estável.

Segundo Leontiev (1987), existem dois momentos em que o processo de formação da personalidade tem grandes saltos qualitativos, o primeiro é na infância pré-escolar e o segundo é na adolescência, por serem momentos de mudanças decisivas na inserção dos indivíduos nas relações sociais. No que se refere à infância pré-escolar, o autor esclarece a contradição que alicerça esse momento do desenvolvimento, mostrando que, nesse período, a conduta da criança é controlada por fatores externos, de modo que fica fácil atrair sua atenção, no entanto, contraditoriamente, ela se distrai com facilidade. Leontiev (1987) destaca que o principal aspecto relacionado a essa característica é o fato de que nesse período a criança não possui uma hierarquia de motivos organizada psicologicamente, por isso ela está suscetível aos motivos-estímulos apresentados externamente, apesar de já existirem alguns enlaces internos que organizam seus motivos, que se encontram em uma formação primária.

$\mathrm{Na}$ transição que caracteriza esse período, a criança já tem condições de realizar ações para as quais não está imediatamente motivada, mas que produzirão o acesso a outra atividade motivante. No entanto, caso haja em seu campo perceptual outros estímulos que a atraiam, ela tenderá a se distrair de seu propósito inicial. Assim, o autor ressalta que, nesse período, a ação da criança é reativa-circunstancial e encontra-se em transição para um comportamento voluntário. Mukhina (1995) acrescenta que é na instabilidade dessa transição, denominada como crise dos três anos, que se dá a tomada de consciência da criança no que se refere à ampliação de suas possibilidades de ação na relação com os adultos que cuidam dela.

Diante dessas características, torna-se compreensível a intensidade dessa crise e evidencia-se porque é comum que o adulto encontre dificuldade no trato com a criança que se encontra nessa condição. Nesse momento, a base sob a qual se potencializa ou se ameniza interações conflitivas adulto-criança reside no descompasso entre a necessidade da criança de exercitar plenamente os alcances de seu desenvolvimento, que a motiva a mostrar autonomia em relação ao adulto, e na forma como os adultos responsáveis por orientar sua conduta exercem esse 
papel.

Uma das principais formas de reação da criança em relação a esse descompasso manifesta-se na resistência que a criança passa a oferecer em relação às orientações do adulto, denominada por Vigotski (1996) como negativismo, teimosia, rebeldia ou insubordinação. O negativismo ocorre nas situações em que a criança se nega a atender a orientação do adulto, motivada pelo ato de negar em si, ou seja, não se trata de uma recusa ligada à natureza da atividade proposta pelo adulto e sim da necessidade de agir contrariamente ao que foi proposto como forma de se auto afirmar. Já a teimosia não envolve recusa a uma orientação prévia e sim uma exigência elaborada pela criança, da qual não abre mão, ainda que o que está sendo exigido por ela não lhe desperte um interesse intenso. Para o autor, as situações em que a criança apresenta reações exageradas e desproporcionalmente intensas, em situações de conflito com o adulto, correspondem à rebeldia, que se diferencia da insubordinação, devido ao fato de que a última é motivada atos vinculados ao interesse por afirmar sua independência em relação ao adulto e sobressair-se em situações diversas, portanto, não se restringe a reações exageradas em uma interação conflitiva.

Tomados em sua aparência, esses atos de resistência infantil podem ser compreendidos genericamente como conduta opositora ou desobediência; entretanto, de acordo com o exposto acima, o autor destaca que se trata de processos psicológicos que se diferenciam conforme o aspecto que motiva a ação da criança e essa diferenciação é essencial para que o adulto adote maneiras mais eficazes para intervir de modo favorecer desenvolvimento integral da criança. Mukhina (1995) destaca que, nessa transição, a resistência da criança é dirigida, principalmente, para os adultos que lhe prestam cuidados constantemente, pois a percepção das novas capacidades em evolução incita-lhe a buscar ativamente um novo lugar nessa relação. Desse modo, cabe ao adulto coordenar as mudanças possíveis, visto que:

[...] As tentativas de continuar a dar o mesmo tratamento anterior incrementam essa conduta negativa, que perdura durante toda a idade pré-escolar. $\mathrm{O}$ tato dos adultos, concedendo à criança a máxima autonomia possível, geralmente suaviza a atitude negativista. (Mukhina, 1995, p. 151). 
Como vimos, a psicologia histórico-cultural, a partir das leis gerais que elucidam a complexidade das forças motrizes que impulsionam a evolução do psiquismo, articuladas com análise das manifestações regulares que indicam a dinâmica dessa evolução, apresenta um arsenal teórico que nos possibilita captar as regularidades do desenvolvimento humano, sem tipificar a forma como tais regularidades se manifestam em cada caso, tomando-as como padrões estáticos de comportamentos advindos de processos exclusivamente individuais. Nessa medida, subsidia análises que buscam compreender a gênese dos atos infantis em sua concreticidade, conduzindo-nos a tomar as condições em que cada criança age como fator interveniente no processo de produção de seus diversos modos de ação.

\section{Condições de ensino na educação infantil e o processo de produção de queixas escolares à luz da psicologia histórico-cultural}

Como vimos, a perspectiva histórico-cultural subsidia uma explicação teórica sobre a evolução do desenvolvimento infantil que coloca em relevo a organização das condições de ensino. Nesse sentido, Elkonin (1987) deixa claro que a aplicação prática dos conhecimentos relacionados aos processos que ocorrem ao longo dos períodos do desenvolvimento psíquico está diretamente ligada às condições em que se dá a educação da criança. Com base na exposição sobre as leis gerais do desenvolvimento e sobre as regularidades psíquicas presentes na transição entre a primeira infância e a idade pré-escolar, apresentaremos uma análise das incoerências entre a forma como estão organizadas as condições de ensino presentes nas situações A, B e C, descritas no item 2, e as necessidades psíquicas das crianças que se encontram nesse momento do desenvolvimento.

Inicialmente, cabe destacar aspectos metodológicos que convergem para o mesmo tipo de equívoco organizativo, entre os quais evidenciamos a centralidade da relação criança/objeto em detrimento da centralidade da mediação do professor ou educador. Nas três situações descritas, podemos notar que a forma como as atividades centrais são propostas para as crianças segue o seguinte modelo: 
disponibilização de estímulos supostamente atraentes para que a criança se engaje em interagir, exclusivamente, com o objeto da atividade proposta e tentativas de coibir verbalmente atos contrários a esse engajamento. Esse modelo funda-se na suposição espontaneísta de que o engajamento esperado emerge da interação com o objeto e mantém-se enquanto durar essa interação.

Nas três situações, os professores e educadores encontram-se na condição de meio de acesso das crianças aos objetos de cada atividade. Disso resulta que em nenhuma das situações é observada a inserção de professores e educadores no conteúdo da atividade proposta, visto que se encontram envolvidos com atividades diferentes daquela que propuseram para as crianças. Tal perspectiva é contrária ao que propõe a psicologia histórico-cultural, pois esta afirma a centralidade do professor, situando o objeto das atividades como componente de mediação na relação que se estabelece entre o professor e os alunos.

Nem mesmo na situação $B$, em que a atividade-guia das crianças é a objetal-manipulatória, a premissa apresentada se sustenta, pois, como propõe Elkonin (1987), o objeto é um componente das relações sociais, sendo, portanto, um objeto social, apresentado e significado pelos adultos, o que o torna um dos elos de ligação da criança com seu entorno social. Porém, seu imenso interesse inicial pelas cores e formas do objeto se esvai rapidamente se outro estímulo lhe provocar interesse e esse novo estímulo pode ser a maciez de um braço da outra criança que está sentada ao seu lado. Sendo assim, “[...] é preciso organizar o ambiente no sentido de evitar condições propícias para a mordida” (Pasqualini, Ferracioli, 2012, p.154), o que não é observado na situação B, em que as crianças interagem com brinquedos e entre si, sem a presença de um adulto exclusivamente voltado para coordenar essas interações. A influência da coordenação de um adulto sobre as ações das crianças fica evidente ao notarmos que a presença da pesquisadora gesticulando e cantando músicas infantis mobiliza o foco da atenção das crianças, induzindo-as a reproduzir os gestos, o que contribui para a redução das manifestações de irritação e, logo, para a diminuição do barulho do ambiente.

De modo semelhante, notamos na situação A que a forma como as condições de ensino foram organizadas não atende a algumas das necessidades 
psíquicas características de cada faixa etária. A análise com relação ao uso de filmes na rotina pedagógica foge aos propósitos desse trabalho; entretanto, tomando o filme como objeto da atividade proposta, a turma cujas crianças têm de três a quatro anos deveria ser a primeira a sair da sala de vídeo, visto que aos 3 anos a criança está mais suscetível a se engajar em ações voltadas aos estímulos imediatamente disponíveis aos seus sentidos do que as crianças com cinco anos. Além disso, a amplitude de domínio da linguagem e a ampliação da capacidade de concentração possibilitam que a criança de 5 anos consiga se interessar mais pelos diálogos do filme do que as crianças com 3 anos.

Soma-se a isso o fato de que se trata de um período em que regularmente as crianças apresentam comportamentos relacionados à chamada crise dos 3 anos em suas diversas formas de manifestação, como vimos no item 3. Assim, manter as crianças dessa faixa etária por mais tempo na sala de exibição de vídeo amplia a probabilidade de ocorrência de situações conflitivas, já que a atividade proposta tende a se tornar desinteressante muito rapidamente.

No que se refere à situação $\mathrm{C}$, fica evidente que Vítor age tendo Dora como alvo, pois contraria a sua orientação de brincar com o carrinho sobre a mesa sem levantar-se da cadeira em que ela o colocou. É notável que seus atos iniciais de oposição (tais como: circular o carrinho por toda a mesa interferindo na brincadeira de outras crianças, simular o som do carro aumentando cada vez mais o tom da voz) vão revelando a intensificação de sua insubordinação a medida que Dora permanece concentrada em recortar os coraçõezinhos e não lhe dirige atenção. Então, a atitude de insubordinação evolui para o ato de percorrer toda a sala com o carrinho e, finalmente, sair na sala. Vitor ateve-se à brincadeira como forma, porém o conteúdo de seus atos estava centralmente vinculado à sua necessidade de autoafirmação perante o adulto.

É digno de destaque que, antes de sair da sala, ato que corresponde ao ápice de sua insubordinação, Vitor busca a reação dos adultos olhando para Dora e depois para a câmera manuseada pela pesquisadora. Essa atitude pode estar relacionada à necessidade de um controle externo do campo perceptual da criança, apresentando novos motivos para suas ações; pois Leontiev (1987) mostra que, aos 3 anos, sua motivação para agir está imediatamente relacionada 
ao seu campo perceptivo. Assim, tendo em vista que a ação da criança é constantemente influenciada por motivos externos, seria imprescindível a intervenção de Dora no sentido de enriquecer o conteúdo das brincadeiras propostas pelas crianças na situação descrita.

Tratando-se de crianças que se encontram no período de transição entre a primeira infância e a idade pré-escolar, como é o caso de Vitor, a intervenção terá seu êxito diretamente proporcional ao grau de fidedignidade da análise que deve ser feita pelo adulto em relação à autonomia possível naquele momento e os limites impostos por sua condição de desenvolvimento. Sair da sala e circular pela escola sem acompanhamento de um adulto é uma ação que coloca em risco a sua segurança, no entanto essa atitude se deu como fruto do acúmulo e intensificação de outras tentativas malsucedidas de se sobressair-se aos olhos de Dora. Nessa situação fica evidente que o acúmulo de tarefas alheias ao acompanhamento pedagógico das atividades propostas para as crianças desvirtua o propósito primordial do trabalho de Dora.

Isso nos mostra a urgência de se compreender os efeitos que a lógica de organização da rotina de educação infantil em torno de datas comemorativas vem produzindo do ponto de vista dos objetivos a serem alcançados com as crianças, para que não se mantenham práticas arraigadas em defesa das "tradições culturais" e em detrimento de um trabalho pedagógico voltado para o desenvolvimento pleno das crianças.

\section{Considerações Finais}

Nesse estudo, problematizamos o processo de produção da queixa escolar na educação infantil, esmiuçando algumas determinações relacionadas à organização das condições de ensino que vem dando sustentação a esse fenômeno, e apresentamos um arsenal teórico que subsidia novas maneiras de aproximação do problema em pauta.

Tal como apontamos na introdução desse texto, Patto (1999) apresenta análises que explicitam que a educação escolar burguesa reproduz aspectos das relações estabelecidas na sociedade capitalista; ou seja, do mesmo modo que a sociedade produz queixas em relação aos indivíduos que não se ajustam às 
expectativas sociais pré-estabelecidas, a escola, como instância social a serviço dessa expectativa, vai queixar-se das crianças que não agem de acordo com o esperado para cada idade do ponto de vista do professor.

Ocorre que, como vimos, essa expectativa sobre o que é esperado para cada idade tem as mais diversas fontes de formulações científicas e pseudocientíficas, as quais interferem nas escolhas que as equipes escolares adotam para organizar as condições de ensino. As situações analisadas ilustram formas organizativas que implicam em sofrimento, produzido pelas condições de ensino para as crianças e pelas condições de trabalho para professores, revelando alguns desafios enfrentados diariamente pelos professores em geral, com destaque para os que atuam na educação infantil.

Esse sofrimento relaciona-se ao fato de que, na atividade escolar, as condições de ensino representam o cenário em que se efetiva a luta entre a alienação e desenvolvimento humano, a qual está ontologicamente vinculada à atividade docente, fazendo-se presente mesmo que o professor não tenha clareza de que esta luta está se efetivando em seus atos educativos. Urge qualificarmos esses atos conferindo-lhes intencionalidade fundamentada pelo conhecimento científico disponível, tendo em vista que nossas análises mostraram as incompatibilidades entre o modo como as condições de ensino estão organizadas e as necessidades psicológicas que caracterizam os períodos do desenvolvimento infantil.

Diante disso, introduzimos esse estudo compartilhando nossa indignação em relação ao avanço dos mecanismos de patologização do comportamento infantil e a consequente medicalização de crianças desde a primeira infância para afirmar tratar-se de uma questão ética e concluiremos reiterando que:

Ética, numa perspectiva histórico-dialética, é querer um certo bem geral, uma vez que existam as condições materiais e técnicas indispensáveis para a concretização desse bem. A cada momento histórico, o homem enfrenta novos problemas; quando descobre as condições para a sua solução, a determinação política de resolvêlos torna-se um dever, isto é, uma questão ética. Pesquisa é descobrir novos conhecimentos que possibilitem a solução dos novos problemas enfrentados pela humanidade. Em outras palavras, a pesquisa transforma o problema técnico em questão ética. (Nosella, 2008, p. 255). 
Assim, destacamos que a psicologia histórico-cultural reúne um conjunto de conhecimentos científicos sobre a dinâmica do desenvolvimento do psiquismo humano nos fornecendo a possibilidade de elaborar novas técnicas para superar velhos problemas. Para tanto, cabe reiterar que as premissas para a superação das práticas típicas do modelo escolar burguês estão na própria escola burguesa, o que nos conduz à defesa da luta pela apropriação de conhecimentos técnicocientíficos que nos auxiliem a organizar as condições de ensino, colocando-as a serviço do máximo desenvolvimento possível para os indivíduos na situação concreta atual, visto que a precariedade do desenvolvimento humano favorece a formação de indivíduos reféns da ideologia dominante e, portanto, fadados a agir em prol da mera reprodução da sociedade vigente.

\section{Referências}

ARCE, A.; MARTINS, L. M. A Educação Infantil e o Ensino Fundamental de Nove Anos. In: ARCE, A.; MARTINS, L. M. (org.). 3. ed. Alínea: Campinas, 2013.

BRASIL, Ministério da Educação. Base Nacional Comum Curricular. Brasília, 2017. Disponível em: http://basenacionalcomum.mec.gov.br/wp-content/uploads/2018/02/bncc20dez-site.pdf. Acesso em: 30 de março de 2019.

BRASIL. Ministério da Saúde. Recomendação No 019, de 08 de outubro de 2015. Recomendações do Ministério da Saúde para adoção de práticas não medicalizantes e para a publicação de protocolos municipais e estaduais de dispensação de metilfenidato para prevenir a excessiva medicalização de crianças e adolescentes. Disponível em: https://portalarquivos2.saude.gov.br/images/pdf/2015/outubro/01/Recomenda----es-paraPrevenir-excessiva-Medicaliza----o-de-Crian--a-e-Adolescentes.pdf. Acesso em: 29 de março de 2019.

BRASIL, 1998. Ministério da Educação e do Desporto, Secretaria de Educação Fundamental. Referenciais curriculares nacionais para a educação infantil. Brasília: MEC/SEF, 1998. Disponível em: http://portal.mec.gov.br/seb/arquivos/pdf/volume3.pdf. Acesso em: 22 jul. 2018

BRASIL, 1996. Planalto do Governo. Lei de Diretrizes e Bases. Lei No 9.394, de 20 de dezembro de 1996. Estabelece as diretrizes e bases da educação nacional. Brasília, 1996. Disponível em: http://www.planalto.gov.br/ccivil_03/LEIS/L9394.htm. Acesso em: 22 jul. 2018.

BRECHT, B. A vida de Galileu. São Paulo: Abril Cultural, 1977.

DIAS, L. C. D. Considerações acerca do transtorno de conduta. 2012. 19 f. Monografia (Especialização) - Curso de Psicologia, Universidade Federal do Rio Grande do Sul, Porto 
Alegre, 2012. Disponível em:

$<$ https://www.lume.ufrgs.br/bitstream/handle/10183/49109/000828783.pdf?sequence=1 >. Acesso em: 18 abr. 2016.

DUARTE, N. Concepções afirmativas e negativas sobre o ato de ensinar. Cad. CEDES [online, v. 19. N. 44, p. 85-106, abril. 1998. Disponível em: http://www.scielo.br/scielo.php?script=sci arttext\&pid=S0101-

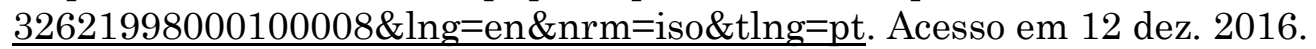

ELKONIN, D. Sobre el problema de la periodizacion del desarrollo psíquico en la infancia. In: DAVIDOV, V. \& SHUARE. M. (org.). La psicologia evolutiva y pedagógica en la URSS. Moscú: Editorial Progresso, 1987.

KEENAN, K.; SHAW, D. The development of coercive family processes: The interaction between aversive toddler behavior and parenting factors. In: J. McCord (Org.). Coercion and punishment in long-term perspectives. Cambridge: Cambridge University Press, 1988.

KOPNIN, P. V. A dialética como lógica e teoria do conhecimento. Rio de Janeiro: Civilização Brasileira, 1978.

LEONTIEV, A. N. El desarrollo psíquico del niño en la edad preescolar. In: DAVIDOV, V.; SHUARE. M. (org.). La psicologia evolutiva y pedagógica en la URSS. Moscú:

Editorial Progresso, 1987.

MUKHINA, V. Psicologia da idade pré-escolar. Tradução: Claudia Berliner. São Paulo: Martins Fontes, 1995.

NOSELLA, P. Ética e pesquisa. Educação \& Sociedade, Campinas, v. 20, n. 102, p. 255273, jan./abr. 2008

PASQUALINI, J. C.; FERRACIOLI, M. U. A questão da agressividade em contexto escolar: desenvolvimento infantil e práticas educativas. In: ARCE, A.; MARTINS, L. M. (org.). Ensinando aos pequenos de zero a três anos. 2. ed. Campinas: Editora Alínea, 2012.

PASQUALINI, J. C. Princípios para a organização do ensino na perspectiva históricocultural: um estudo a partir da prática do professor. 2010. 268 f. Tese (Doutorado em Educação Escolar) - Faculdade de Ciências e Letras, Universidade Estadual Paulista, Araraquara.

PATTO, M. H. S. A produção do fracasso escolar: histórias de submissão e rebeldia. São Paulo: T. A. Queiroz, 1999.

PATTO, M. H. S. O fracasso escolar como objeto de estudo. Cadernos de pesquisa, São Paulo, n. 65, p. 72-77, mai. 1988.

PATTO, M. H. S. Psicologia e ideologia: uma introdução crítica à psicologia escolar. São Paulo: T. A. Queiroz, 1984.

PATTO, M. H. S. Privação cultural e educação pré-primária. São Paulo: José Olympio editora, 1973. 
PORTELINHA, A. M. S.; ZOIA, E. T.; PASQUALOTTO, L. C.; COELHO, R. T.;

SBARDELOTTO, V. S. A educação infantil no contexto das discussões da Base Nacional Comum Curricular. Revista Temas \& Matizes, Cascavel, v. 11, n. 20, p. 30-43, jan./jun., 2017.

PRADO JÚNIOR, C. Dialética do Conhecimento: história da dialética / lógica dialética. 3. ed. São Paulo: Brasiliense, 1960.

ROSSLER, J. H. A dimensão retórica e valorativa do núcleo teórico-conceitual do ideário construtivista. In: ROSSLER, J. H. Sedução e alienação no discurso construtivista.

Campinas: Autores Associados, 2006. Coleção Educação Contemporânea.

SAGAN, C. Ciência e Esperança. In: $O$ mundo assombrado pelos demônios. São Paulo: Companhia das Letras, 1996.

SAVIANI, D. Perspectiva marxiana do problema da subjetividade-intersubjetividade. In: DUARTE, N. et al. Crítica ao fetichismo da individualidade. Campinas: Autores Associados, 2004.

SILVA, C. R. da. Análise da dinâmica de formação do caráter e aprodução da queixa escolar na educação infantil: contribuições à luz da psicologia histórico-cultural e da pedagogia histórico-crítica. 2017. 261 f. Tese (Doutorado em Educação Escolar).

Faculdade de Ciências e Letras, Universidade Estadual paulista Júlio de Mesquita Filho, Araraquara, 2017.

SOUZA, B. P. (org). Orientação à queixa escolar. São Paulo: Casa do psicólogo, 2007.

SOUZA, M. C. B. R. de. A concepção de criança para o enfoque histórico-cultural. 2007. 154 f. Tese (Doutorado em Educação). Faculdade de Filosofia e Ciências, Universidade Estadual paulista Júlio de Mesquita Filho, Marília, 2007.

VIGOTSKI, L. S. Sete aulas de L. S. Vigotski sobre fundamentos da pedologia. Organização [e tradução]: Zoia Prestes e Elizabeth Tunes. Trad. Claudia da Costa Guimarães Santana. 1ª ed. Rio de Janeiro: E-papers, 2018.

VIGOTSKI, L. S. Psicologia Pedagógica. Tradução: Paulo Bezerra. São Paulo: Martins Fontes, 2010. (Coleção Textos de Psicologia).

VIGOTSKI, L. S. Obras escogidas. Tradução: Lydia Kuper. Madrid: Visor Distribuiciones, 1996. v. 4. 